\title{
Quality of Work Life and Academic Dual - Career Couples
}

\author{
P.Jyothi*, Dr.Sita Neelakantan** \\ *Research scholar, Sathyabama University, Tamilnadu, India. \\ ** Professor \& Head, Department of management studies, SMEC, Tamilnadu, India.
}

\begin{abstract}
In India, studies on Dual-career couples is still new concept to explore much, though four decades have passed since the phrase was first introduced. No initiatives were taken to identify $Q W L$ in dual careercouples in India, in establishing relationship between their job performance and Quality of Work Life. Thus the study aims to investigate the QWL dimensions and dual-career couple's job performance through quantitative survey on 68 full-time academic dual -career couples. The survey is conducted based on a structured questionnaire designed with 5-point Likert-scale questionnaire. The sample includes private universities in India. The results showed the positive influence of QWL factors on dual career couples job performance and it shows that there is no significant difference between male and female among Dual career couple in terms their Quality of work life, which indicates the implementation and enhancement of QWL programmes, can contribute to improvements in the performances of academic dual-Career couples.
\end{abstract}

Key Words: Quality of work life, academic dual career couples, Performance, private universities, India

\section{Background Of The Study}

The term"dual-career" was first coined in 1969 by a European academic couple, Rapoport \& Rapoport (1969), Rapoport \& Rapoport (1971). Since then this term has become quite established, other expressions are "coupled careers", Bernice (1994),"conjoint career couple" Adler et al. (1989) or "coordinated career" couple, Butler \& Paisley (1980). These last two terms, however, refer to couples where both partners pursue careers in the same field or whose work activities overlap, Butler \& Paisley (1980), and who are, therefore, professional colleagues in addition to being partners, Adler et al. (1989). According to the Rapports, dual career couples differ from dual-earner families/couples. In dual-career couples, both partners pursue an occupational career occupying or seeking jobs which are characterized by high professional standards, a high degree of commitment and a developmental sequence. Emerging socioeconomic changes shape family dynamics. Today, dual-earner families represent nearly $50 \%$ of families in the labor force. The traditional breadwinner/homemaker family accounts for less than $20 \%$ of families. Seventy percent of mothers with children work at least part time. The dramatic increase in the percentage of women in the labor force means that couples are reexamining traditional divisions of labor around paid work, house work, child care/elder care, and community service.

Dual-career couples have been defined as "a married couple where both husband and wife have different careers", HR Dictionary, (2011). "For dual-career couples and working women, balancing work demands with personal and family responsibilities is difficult to do", Jackson and Mathis, (2007), and the situations becomes even more challenging where dual career couples have a child or children. Organizations have to introduce specific measures and initiatives in order to assist their dual-career couples and parent employees to achieve work-life balance, and thus to achieve their commitment and contribution to the achievement of organizational objectives in an effective manner.

Dual career faculty couples face a unique set of challenges within the academic world. While these couples face the same challenges as all dual career couples, faculty couples have to also combine these normal stresses with special challenges of working as a faculty member. The first challenge is the original job search and finding two positions. The next challenge is to both make it through the tenure and promotion process. The third challenge is to have advancement opportunities. Along the way, the couple has to work together to develop a work/life balance plan to provide an environment for each person within the pair to thrive toward his/her career goals and personal goals. Besides balancing the day-to-day activities of a functioning household, couples must agree on timing for or if they will start a family and advancement opportunities for each.

Having one faculty member in the family is very challenging. However, having two faculty members in the family makes life even more interesting. Today's work environment involves more and more dual career couples where both partners work full-time. Additionally many faculty meet their significant others during school creating an environment with more dual career couples than in the past. Dual career couples have a different set of challenges than couples that are single-income or one-income dominant. Dual career faculty also has the challenge of the tenure process and advancing in a system that is often less flexible than many industrial jobs. Sometimes the dual career situation is complicated because universities are located in remote areas that lack other career opportunities outside of the university. The key for dual career couples is to establish a system 
to help them balance their career and personal activities. For each couple the dynamics are going to be a little different depending on your personal situation, for example -- university location, career aspirations, your age, kids/no kids, aging relatives, and hobbies. As our career and family have changed and grown, we have gone through different phases and have recently started a new phase as Kirk became the Dean of Engineering at MSU in January of 2005. These new roles will provide a new opportunity for us to learn to balance. In this paper we outline some of our personal tips as well as summarize lessons learned and advice over the last fifteen years as dual career engineering faculty.

\section{Review Of Literature}

It has been stated that "two-career partners need the dexterity to balance not only career and family life but also her and his careers so that both spouses prosper professionally in what they see as a fair way" Lamanna and Riedman, (2006). However, in reality finding "a fair way" proves to be a highly challenging task to accomplish and it is rarely achieved without the help offered by employers. Ayesha Tabasum, Tasnuva Rahman and Kursia Jahan ,( 2011) The study reveals that a significant difference exists between male and female employees QWL and in the following factors of QWL; adequate and fair compensation, flexible work schedule and job assignment, attention to job design, and employee relations. As a significant number of female participants from the labor force are now entering in the banking sector, this finding may add value to the management of the banks. The study reveals that a significant difference exists between male and female employees QWL and in the following factors of QWL; adequate and fair compensation, flexible work schedule and job assignment, attention to job design, and employee relations. As a significant number of female participants from the labor force are now entering in the banking sector, this finding may add value to the management of the banks.

Kelly and Littlefield ,(2004) The implications for business and industry in northern-lower Michigan which can be generalized for other organizations in rural geographic areas of America, is the findings suggest members of dual-career families perceive health insurance and dental insurance as most supportive in alleviating work-life conflict. Organizations may wish to evaluate their personnel practices to ensure that they include healthcare and dental insurance. In addition, non-traditional benefits such as employee sick leave for child's illness, flexible work hours, and leave without pay-position assured, are perceived as more supportive than traditional benefits such as maternity benefits and cafeteria approach to benefits. Human resource managers may want to re-evaluate their existing personnel practices to incorporate practices relating to flexible hours and time off to attend to a child's illness as part of their practices and examine the possibility of flexible work hours. The findings also suggest that members of dual-career families indicate that monetary support of community childcare facilities is perceived as more supportive at a mean of 3.97 than on-site childcare at a mean of 3.8. Organizations may want to evaluate the expense of creating an on-site childcare facility versus monetary support of community child-care facilities since the subjects indicate that they find monetary support of child-care facilities more supportive.

Processes. Akdere (2006) holds that researchers interested in the concept of quality of work life are looking for new mechanisms to help employees to balance their work and personal lives. According to Chan, and Einstein, (1990) people also conceive of QWL as a set of methods, such as autonomous work groups, job enrichment and high involvement aimed at boosting the satisfaction and productivity of workers. Thus QWL is a comprehensive construct that includes an individual's job related well being and the extend to which work experience are rewarding fulfilling and devoid of stress and other negative personal consequences. According to Guna Seelan Rethinam, Maimunah QWL is a multi-dimensional construct, made up of a number of interrelated factors that need careful consideration to conceptualize and measure. It is associated with job satisfaction, job involvement, motivation, productivity, health, safety and well-being, job security, competence development and balance between work and non work life and he concluded as QWL from the perspective of IT professionals is challenging both to the individuals and organizations. According to the rising number of two income households is heightening the concern for employees QWL. Uli, Che Rose, Beh and Idris (2006) said that the rising number of the two-income household is heightening the concerns for employees' quality of work life. Female participation at work increasing, thus males and females independently will need to take care of both work and home. By means of this, extra focus is required to take care of work and residence. These caused an imbalanced proportion of time spend and cause most of this people live a less quality life. Given the female participation at work is increasing, it is apparent that males and females independently will need to take care of both work and home. Therefore, quality of work experience rather than work perse became the focus attention and workplace wellness is crucial in promoting healthier working environments.

Walton theoretical framework used in the study for measuring Quality of Work Life of the dual career couples includes following factors;

i) Satisfaction with fair payment: Sufficient salary for a full time work and enough payment to cover current life requirements considering social criteria; 
ii) A safe and healthy working environment: It consists of safe physical and mental working situations and determining logical working hours;

iii) An opportunity for continual growth: Having good conditions to increase personal empowerment and skills; iv) Social relationship in organizations: It refers to the employee's perception of social responsibilities of the firm;

V) Balanced role of work: Existence of equilibrium between work life and other sections of employee's life

vi) Social Coherent in the work organization: Sense of belonging to organization

vii) Regulations and rule orientation: The situation for employees to express their opinions without being afraid of to managers;

viii) Developing human capacities: Includes different opportunities for personnel such as independency at work having the authority to access the related information for their tasks.

\section{Objectives of the study}

Literature on past studies proved the various domains of quality of work life and aspects of dual- career couples. This study is specifically designed in a view point to achieve following objectives.

- To identify and determine the critical factors of Quality of work life among Academic dual-Career couples in the private universities in India.

- To study whether there is significant gap among the academic female and male dual career couple with respect to their quality of work life.

- To suggest some measures to improve quality of work life of Academic dual-Career couples.

\section{Research Methodology}

Research Design is the blue print of the various methods for conducting the research projects. It includes the procedures for obtaining the information needed, the way in which they are processed and the method of presentation of the result to solve the research problems. Even though the research designs are plenty, the present study followed the 'Descriptive' research Design. Since the present study has made an attempt to identify the existence of QWL in academic dual career couple perspective and also finds out the important QWL factors in those couples in balancing their lives, thus it is descriptive in nature.

\section{Sampling Procedure}

The sampled Academic couple from private universities of India was 108 couples. The address of the above said couples had been collected from the respective university. The half of the questionnaires had distributed to respondents in person and the remaining was sent through the spouses of the respondents. The response from the couples was 89 and the questionnaires were accepted as couples only, which denotes the response rate of 82. Since the study focuses on both the couple's perspective on QWL at private universities, the couples who had completed both questionnaire (wife and husband) had been included for further analysis. The completely filled questionnaires were only 67 and final response rate is 62 . Hence, the applied sampling procedure is convenient in nature.

\section{Development of the Measuring Instruments}

According to Loscocco and Rochelle (1991), the most common assessment of QWL is the individual attitudes. This is because individual work attitudes are important indicators of QWL. The ways that people respond to their jobs have consequences for their personal happiness and the effectiveness of their work organizations (Rose et al 2006). Thus a structured questionnaire was designed based on Walton's (1975) theory of QWL for achieving the objectives of the study. As indicated in the literature review, several authors and researchers considered Walton's theory for determining QWL in their studies. The relevant details about the various concepts and terms used in the questionnaire have been identified with the help of review of previous studies and also with the help of experts in relevant fields. Walton (1975) identified eight factors related to Quality of work life that has been drawn from 32 variables. The questionnaire used in the survey consisted of two sections. The first section, including 32 statements, was designed to measure the perception by academic dual career couples on eight dimensions of QWL. Respondents were asked to rate their level of agreement on each statement from " 1 " as "strongly disagree" to "5" as "strongly agree". The last section was the demographic information of respondents namely; gender, age, marital status, number of children, education level, income level, position, years of service in the respective university and in higher education sector. To increase reliability and to assure appropriateness of the data collection instrument, the questionnaire was subject to a pilot test conducted with 5 academic couples in affiliated engineering colleges of Chennai city, Tamilnadu. A certain modifications, deletions and additions have been included with the existing Questionnaire. The final draft of the questionnaire was prepared to collect the relevant data. 


\section{Statistical Tools of Data Analysis}

The study is based on the data collected to measure the academic dual career couple perspectives on quality of work life. The measurement scale is Likert scale and thus, it is interval scale. Thus data is in numerical scale and the data is continuous. Though the data is in continuous scale, the Probability-Probability plot (P-P plot) has given the view that it is not distributed normally.

\section{Results And Discussions}

Data collected using questionnaire tested for the reliability. Most popular measure for reliability analysis Cronbach's Alpha using SPSS applied to measure eight dimensions (Satisfaction with fair payment, A safe and healthy working environment, An opportunity for continual growth, Social relationship in organizations, Balanced role of work, Social Coherent in the work organization, Regulation and rule orientation, Developing human capacities )of Quality of work life. Table.1 represents the cronbach's values of Quality of work life and its dimensions. The Cronbach alpha with acceptable cut off point 0.70 demonstrates that all attributes are internally consistent, Fujun, Hutchinson, Li \& Bai 2007). The cornbach's alpha value of overall Quality of work life is 0.913.

Table. 1 Quality of work life of academic dual career couples

\begin{tabular}{|c|c|c|c|c|c|}
\hline \multirow[t]{2}{*}{ QWL Factors } & \multicolumn{2}{|c|}{ Mean } & \multicolumn{2}{|c|}{ Standard Deviation } & \multirow{2}{*}{$\begin{array}{c}\text { Cronbach's } \\
\text { Alpha }\end{array}$} \\
\hline & Men & Women & Men & Women & \\
\hline Satisfaction with fair payment & 2.54 & 2.86 & 0.614 & 0.702 & 0.785 \\
\hline A safe and healthy working environment & 2.84 & 3.14 & 0.705 & 0.514 & 0.912 \\
\hline An opportunity for continual growth & 2.45 & 2.72 & 0.731 & 0.492 & 0.893 \\
\hline Social relationship in organizations & 3.52 & 3.11 & 0.568 & 0.524 & 0.714 \\
\hline Balanced role of work & 3.07 & 2.04 & 0.496 & 0.636 & 0.796 \\
\hline Social Coherent in the work organization & 3.22 & 2.99 & 0.628 & 0.624 & 0.841 \\
\hline Regulation and rule orientation & 2.77 & 2.98 & 0.499 & 0.576 & 0.848 \\
\hline Developing human capacities & 3.42 & 3.27 & 0.786 & 0.685 & 0.892 \\
\hline Total quality of work life & 3.44 & 3.18 & 0.546 & 0.486 & 0.913 \\
\hline
\end{tabular}

Statistical analysis of Quality of work life factors shown in the Table.1. Mean values of QWL factors among men reveals that Social relationship in organizations, balanced role of work, Social Coherent in the work organization and developing human capacities have high influence on overall QWL. Mean values of QWL factors among women reveals that safe and healthy working environment, Social relationship in organizations and Developing human capacities have high influence on Overall QWL.

Table.2.Statistical $\mathrm{T}$ test results

\begin{tabular}{|c|c|c|c|c|c|c|c|}
\hline \multirow{2}{*}{$\begin{array}{l}\text { Statistical test for quality of work life } \\
\text { factors }\end{array}$} & \multicolumn{2}{|c|}{ Leving's testing } & \multicolumn{2}{|c|}{ T testing } & \multirow{2}{*}{$\begin{array}{l}\operatorname{Sig}(2 \\
\text { tailed })\end{array}$} & \multirow{2}{*}{$\begin{array}{c}\text { Mean } \\
\text { difference }\end{array}$} & \multirow[t]{2}{*}{ SD } \\
\hline & sig & $\mathbf{f}$ & $\mathbf{T}$ & df & & & \\
\hline Satisfaction with fair payment & 0.009 & 0.913 & 0.082 & 136 & 0.932 & 0.066 & 0.784 \\
\hline A safe and healthy working environment & 5.68 & 0.016 & 0.318 & 142 & 0.756 & 0.164 & 0.518 \\
\hline An opportunity for continual growth & 1.764 & 0.186 & 1.711 & 144 & 0.924 & 0.906 & 0.524 \\
\hline Social relationship in organizations & 3.483 & 0.068 & 1.382 & 138 & 0.169 & 1.56 & 1.121 \\
\hline Balanced role of work & 3.426 & 0.065 & 1.017 & 143 & 0.321 & 0.483 & 0.486 \\
\hline Social Coherent in the work organization & 1.873 & 0.162 & 0.113 & 138 & 0.908 & 0.107 & 0.941 \\
\hline Regulation and rule orientation & 0.026 & 0.857 & 2.005 & 139 & 0.048 & 1.37 & 0.678 \\
\hline Developing human capacities & 7.168 & 0.007 & 0.283 & 142 & 0.766 & 0.148 & 0.212 \\
\hline Quality of work life & 3.026 & 0.084 & 1.316 & 107 & 0.182 & 6.562 & 4.582 \\
\hline
\end{tabular}

Table 2 shows the the factors of QWL comparatively between Male and Females among dual career couples. According to obtained values of T for QWL factors at $0.05 \alpha$ level which are smaller than the T of the table (1.98), one could conclude that there is no significant difference between QWL in the Male and Females among dual career couples. As the obtained quantities of significant level (sig 2-tailed) show, for seven factors of QWL including Satisfaction with fair payment, A safe and healthy working environment, An opportunity for continual growth, Social relationship in organizations, Balanced role of work, Social Coherent in the work 
organization, Developing human capacities are higher than the $0.05 \alpha$ level. Therefore, the QWL difference between men and women among dual career couples is rejected with 0.95 percent confidence, while there is significant difference, as the eight factors show, in Regulation and rule orientation between men and women dual career couples. The men among dual career couples have a higher level of Regulation and rule orientation than those of women. The reason for this is that the acquired " $t$ " (2.006) on the $0.05 \alpha$ level is bigger than the value of " $\mathrm{t} "(1.98)$.

\section{Conclusions}

The aim of the current research is comparatively study QWL among men and women among dual career couples. Identifying the factors related to faculty QWL is of great importance, because it has positive and significant relation with job performance. Therefore, we can improve Job performance (JP) by changing and manipulating QWL factors, and thus move toward the development of the institution. The main aim of this research is specifying the condition of QWL among men and women among dual career couples. Aim of this study is to examine the difference between the level of QWL among men and women among dual career couples. Results show that there is no significant difference between the levels of QWL. Of the eight factors of QWL, a noticeable difference can be seen only between regulation and rule orientation among the academic dual career couples of the mentioned universities. From regulation and rule orientation point of view, the men among academic dual career couples possess a higher position. In summary, the results of the present research show that: i) The academic dual career couples are on a fairly unfavorable level of QWL, ii) There is no significant difference in QWL in men and women among Academic dual career couples.

\section{References:}

[1] Bernasco and Wim "Coupled careers the effects of spouse's resources on success", 1994.

[2] Bohen, H. H., \& Viveros-Long, A. "Balancing jobs and family life: Do flexible work schedules help?" Philadelphia: Temple University Press, 1989

[3] Butler, Matilda and Paisley, William. "Coordinated-Career Couples: Convergence and Divergence in Dual-Career Couples". Beverly Hills: Sage, 1980 Pp. 207-228.

[4] Chan, C.H. and W.O. Einstein, “Quality of Work Life (QWL): What can unions do?”, SAM Advanced Management J., 1990, pp 17-22.

[5] Dr. Gary Kiger and Dr. Pam Riley, "Helping Dual-Earner Couples Balance Work \& Family Responsibilities".

[6] Fujun, L., Hutchinson, J., Li, D. \& Bai, C., "An empirical assessment and application of SERVQUAL in mainland China's mobile communications industry", The International Journal of Quality \& Reliability Management, Vol 24(3), pp 244-262.

[7] Giedrius Vanagas and Susanna Bihari-Axelsson, "Do gender differences have influence on psychosocial stress, Quality of life and work demands? crosssectional study", Eur J Gen Med 2004; 1(4): 36-41.

[8] Guna Seelan Rethinam and Maimunah Ismail: "Constructs of Quality of Work Life: A Perspective of Information and Technology Professionals", Universiti Putra Malaysia, Malaysia, 2008.

[9] Huzzard J, "The Convergence of the Quality of Working Life and Competitiveness: A Current Swedish Literature Review", National Institute for Working Life, Stockholm, 2003

[10] Lamanna, MA \& Riedman, A, "Marriages \& Families: Making Choices in a Diverse Society", Cengage Learning, 2006.

[11] Loscocco, K. A. \& Roschelle, A. R., "Influences on the quality of work and non-work life: two decades in review", Journal of Vocational Behavior", 1991. Vol 39(2),pp 182-225.

[12] Luthans, F., "Organisational behaviour”. (Eighth edition). Boston, MA: Irwin McGraw-Hill, 1998.

[13] Marc Sher., "Mary Dual Career Couples — Problem or Opportunity?” Vol. 25, No. 2, Ga, zette, 2006, pp 8-17.

[14] Rapoport, Rhona and Rapoport, Robert N., "Dual-career families". Harmondsworth: Penguin Books, 1971.

[15] Rose, R. C., Beh, L. S., Uli, J. \& Idris, K., "Quality of Work Life: Implications of Career Dimensions", Journal of Social Sciences, 2006, Vol 2(2), pp 61-67.

[16] Sekaran, U., Dual-career Families, San Francisco: Jossey-Bass, 1986

[17] Walton, R.E., "Criteria for Quality of working Life. In L.E., Davis, and A.B., Cherns (Eds), The quality of working life”, Newyork: The free press, 1975, Vol. 1. 